$1-2013$

\title{
Navigating TEFRA Partnership Audits in Multi-Tiered Entity Structures
}

Mary A. McNulty

Robert D. Probasco

Texas A\&M University School of Law, probasco@law.tamu.edu

Lee S. Meyercord

Thompson \& Knight, LLP

Follow this and additional works at: https://scholarship.law.tamu.edu/facscholar

Part of the Taxation-Federal Commons, and the Tax Law Commons

\section{Recommended Citation}

Mary A. McNulty, Robert D. Probasco \& Lee S. Meyercord, Navigating TEFRA Partnership Audits in MultiTiered Entity Structures, 15 Bus. Entities 22 (2013).

Available at: https://scholarship.law.tamu.edu/facscholar/1231

This Article is brought to you for free and open access by Texas A\&M Law Scholarship. It has been accepted for inclusion in Faculty Scholarship by an authorized administrator of Texas A\&M Law Scholarship. For more information, please contact aretteen@law.tamu.edu. 


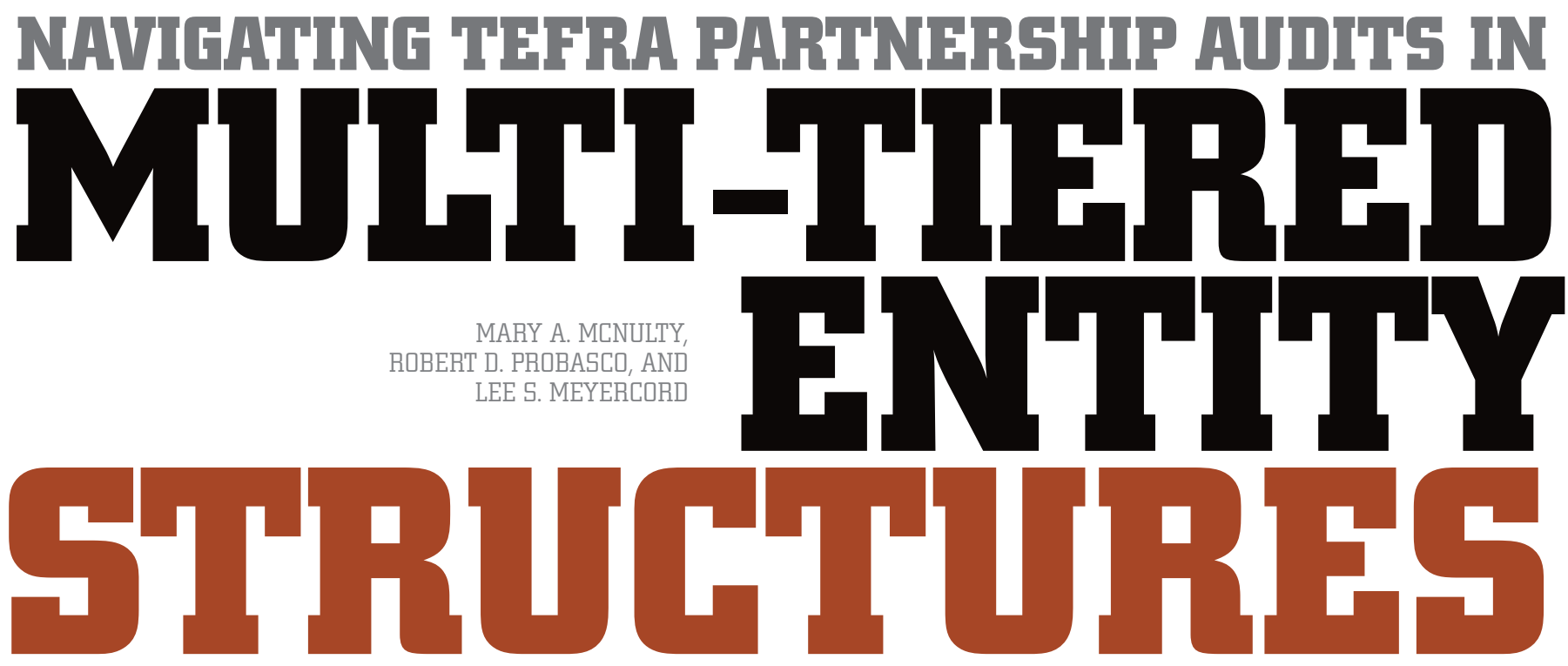

TheTax Equity and Fiscal Responsibility Act of 1982 (TFFRA) established a unified procedure for determining the tax treatment of partnership items at the partnership level rather than the partner level. Although these rules addressed a serious and real administrative problem in the assessment of partnership item deficiencies, they also created a complex process with many new problems and potential traps. One particularly unique set of challenges arises in the context of multi-tiered entities.

Multi-tiered entities are partnerships that have a partnership or other pass-through entity as a partner. The passthrough partner is commonly referred to as a "tier," and the partnership in which it holds its interest is the "source" partnership. The partners who hold an interest in the source partnership through a pass-through partner are "indirect partners" of the source partnership. TEFRA procedures apply to any actual partner and "any other person whose income tax liability under subtitle $\mathrm{A}$ is determined in whole or in part by taking into account directly or indirectly partnership items of the partnership." 1 Thus, this definition picks up pass-through partners and indirect partners and is not limited to those 


\section{$+$}

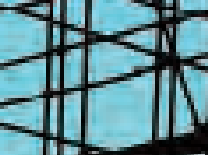

N.

1)

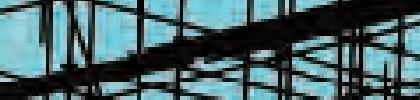
(1)

1

7 (1) 1 HAX ( ( 1 111 C \ I 1 + 720 Hon LE. 1 )

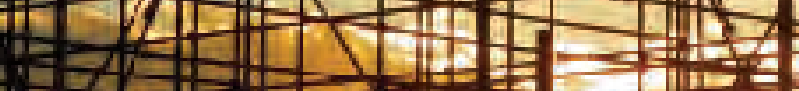
$+1+$ 䏠

(I)

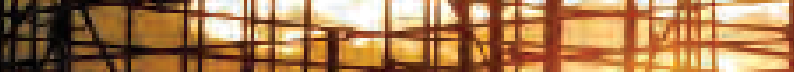

in

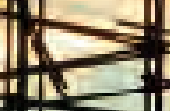

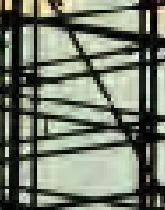

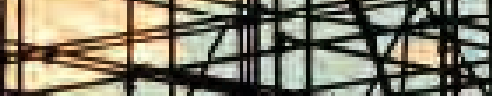
$\angle a^{2}=7+2$ 2

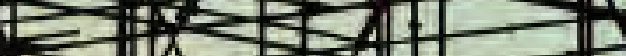
2 42 Tarit

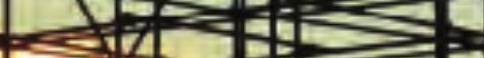


direct partners who receive a Schedule K-1 from the partnership. Pass-through partners include "a partnership, estate, trust, $\mathrm{S}$ corporation, nominee, or other similar person through whom other persons hold an interest in the partnership with respect to which proceedings under this subchapter are conducted." 2 Indirect partners are those partners who own an "interest in a partnership through 1 or more pass-thru partners."3

Pass-through partners and indirect partners face unique issues in navigating the TEFRA rules. For example, TEFRA often shifts the burden of keeping indirect partners informed of proceedings to pass-through partners, and pass-through partners must be aware of their responsibilities under TEFRA to avoid potential liability to the indirect partners. In addition, TEFRA will limit an indirect partner's right to participate in a partnershiplevel proceeding unless the indirect partner takes steps to protect its rights. These issues are becoming increasingly important as the IRS focuses on tiered entities in an effort to increase the tax compliance of high-wealth taxpayers. ${ }^{4}$

This article highlights the unique issues that pass-through partners and indirect partners face in navigating the TEFRA procedures, including:

1. Notice of audit proceedings.

2. Participation in administrative and judicial proceedings.

3. An extended statute of limitations for unidentified partners.

\section{Notice of Audit Proceedings}

The IRS is required to give notice of the beginning of an audit (NBAP) and of the end of an audit through a final partnership administrative adjustment (FPAA). These notices must be given to all partners whose names and addresses are furnished to the IRS (notice partners). ${ }^{5}$ This information is provided to the IRS in either the tax return of the partnership under audit or in a statement that meets the requirements of Reg. 301.6223(c)-1(b).6

Indirect partners are not usually listed on the source partnership's tax return. Therefore, if an indirect partner wants to receive notice, the partner should file a statement with the IRS in accordance with Reg. 301.6223(c)-1(b). This provision requires the statement to identify the partnership and each partner for whom information is supplied; to explain that the statement is furnished to supplement information with respect to the partners in the partnership; to specify the tax year to which the information relates; and to be signed by the person supplying the additional information. Importantly, the statement of an indirect partner will not meet the regulatory requirements if the statement merely refers the IRS to the pass-through partner's return, unless a copy of the return is attached to the statement.7

The Service has no obligation to obtain information not provided to it in the partnership's tax return or by the requisite statement, even if the information is readily accessible to it. For example, in Walthall, 8 three indirect partners did not receive notice from the pass-through partners of a partnership audit. The district court concluded that, while the IRS could have determined the indirect partners' identifying information by looking at the returns of the pass-through partners, the Service was not required to look at those returns or any information other than that required by the statutei.e., the tax return of the partnership under audit or a statement provided to the IRS. ${ }^{9}$

If the IRS obtains the indirect partner's name, address and indirect profits interest in the partnership from the requisite statement, Section 6223(c)(3) requires the Service to provide the NBAP and FPAA to the indirect partners directly. 10 Providing the NBAP and FPAA only to the pass-through partner does not satisfy the statutory requirement that these notices be pro-

MARY A. MCNULTY and ROBERT D. PROBASCO are partners, and LEE S. MEYERCORD is an associate, in the Dallas office of Thompson \& Knight, LLP. Ms. McNulty specializes in IRS audits and appeals, tax litigation, and tax planning. She is the Past Chair of the Section of Taxation of the State Bar of Texas and a former Chair of the Dallas Bar Association Tax Section and the Court Procedure and Practice Committee of the ABA Tax Section. Mr. Probasco specializes in IRS audits, appeals, and tax litigation. He is a Council member, Chair of the Pro Bono Committee, and Vice-Chair of the Tax Controversy Committee of the Section of Taxation of the State Bar of Texas. Ms. Meyercord's practice includes IRS audits and appeals, and tax planning.

TEFRA ISSUES ARE

BECOMING INCREASINGLY

IMPORTANT AS THE IRS

FOCUSES ON TIERED

ENTITIES, IN AN EFFORT

TO INCREASE THE TAX

COMPLIANCE OF HIGH

WEALTH TAXPAYERS.

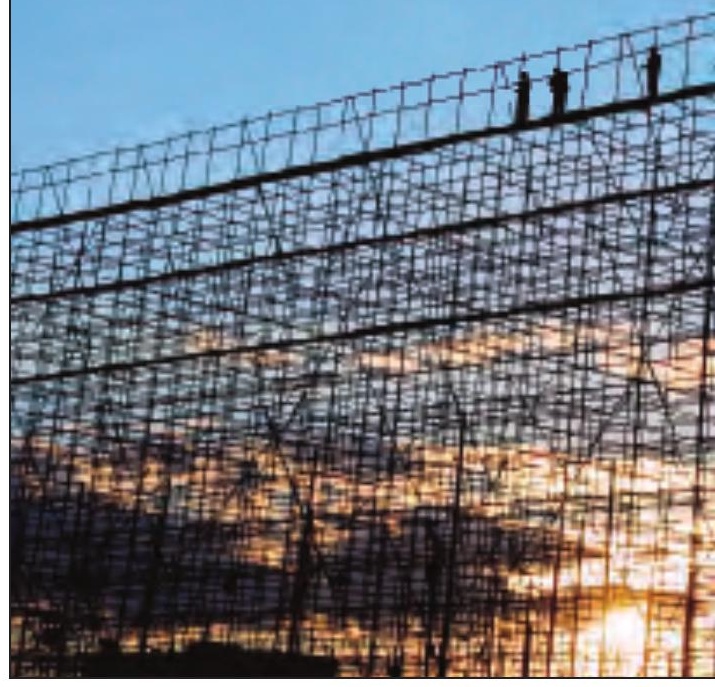

vided to those indirect partners whose identifying information has been provided to the IRS.

If an indirect partner is not a notice partner, the pass-through partner is required to forward any notice to the indirect partners within 30 days of receiving the notice. ${ }^{11}$ In this way, TEFRA places the primary burden for keeping indirect partners informed on the tax matters partner (TMP) and the pass-through partner, rather than the IRS. An indirect partner can generally rely on the pass-through partner to provide notice. However, the partnership proceedings and adjustments still apply to an indirect partner, if the TMP or pass-through partner fails to provide notice. ${ }^{12}$ Therefore, an indirect partner should consider becoming a notice partner to protect its rights.

In particular, an indirect partner will want to take additional steps to ensure that it receives notice in two situations:

- When the pass-through partner has filed for bankruptcy.

- When the indirect partner holds less than a $1 \%$ interest in a large partnership. 


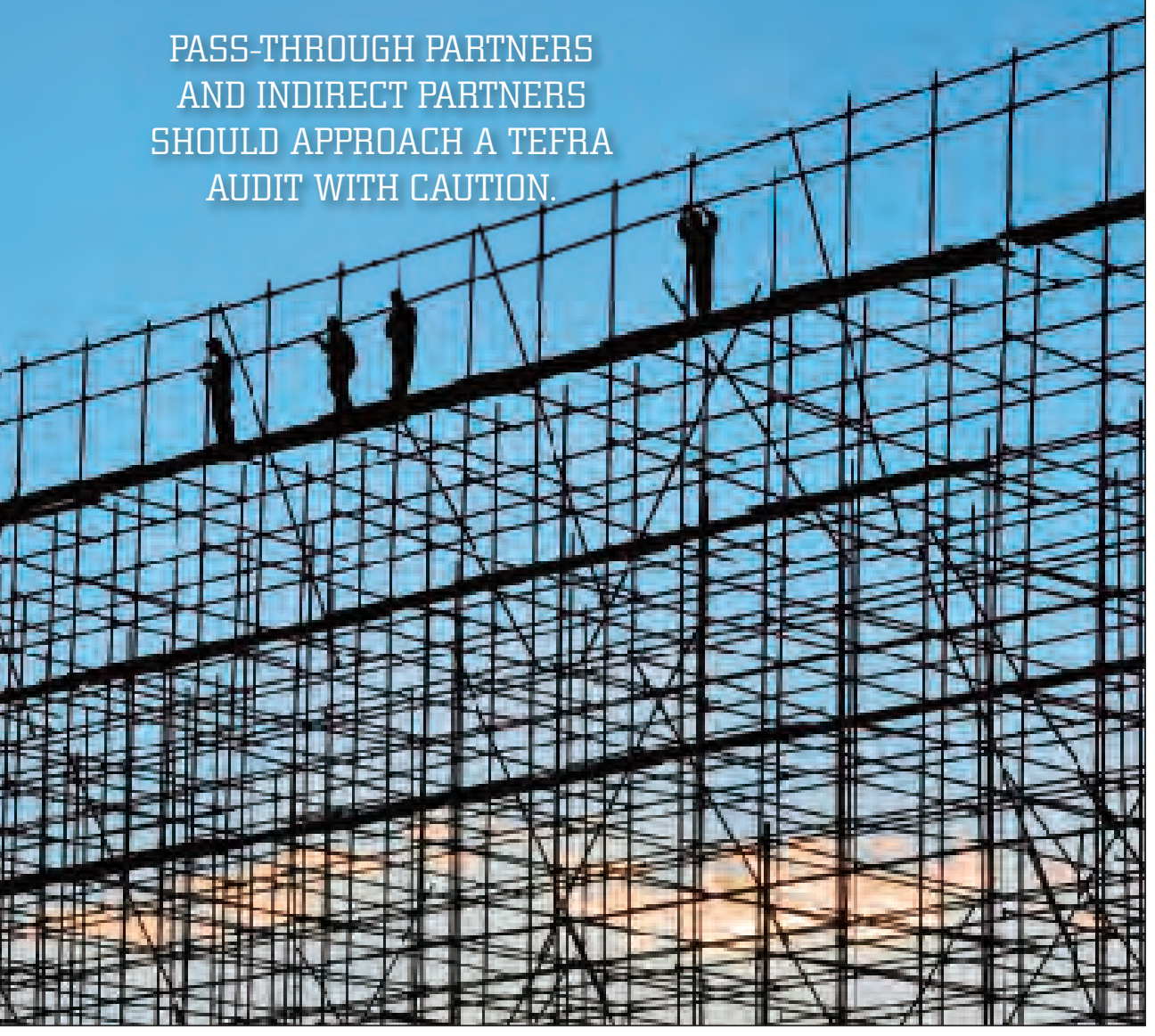

Widely held source partnerships present administrative challenges. The IRS currently faces limitations on its ability to link partnership returns with their partners-a problem that is particularly acute for widely held, multitiered partnerships. ${ }^{19}$ These limitations reduce the audits of large partnerships and, therefore, are prompting various tax reform proposals, such as treating large, widely held partnerships, as C corporations for audit purposes ${ }^{20}$ or even taxing partnerships with income or assets in excess of a certain amount as $\mathrm{C}$ corporations. ${ }^{21}$ One commentator noted that the "shared aversion to TEFRA has led the IRS and partnerships to try to sidestep the law's burdensome notice procedures as much as possible." 22 For example, the IRS may choose to deal with only the TMP, who can bind itself and non-notice partners, and forego issuing partnerlevel notices to notice partners and collecting any tax from them. ${ }^{23}$ To avoid finding itself in this situation, a non-notice partner should take steps to ensure that its rights are protected.

Rights Afforded to All Partners. Any partner, including an indirect partner and a pass-through partner, has the right to participate in the administrative proceeding 24 and the right to file a request for an administrative adjustment (AAR)-i.e., the partnership equivalent to a refund claim. ${ }^{25}$ However, any partner who wishes to participate in the audit must coordinate with the TMP because the IRS is not required to notify any other partner of ongoing audit activities, or to adjust the audit schedule to accommodate them. ${ }^{26}$ An indirect partner's right to participate in the audit, then, depends on his ability to coordinate with the TMP.

Right to File a Protest or Petition for Redetermination. Only notice partners have the right to contest an FPAA by either filing a protest with IRS Appeals or by filing a petition for redetermination. ${ }^{27}$ If an indirect partner would like to preserve this right, the partner should send an identifying statement to the IRS that complies with Reg. 301.6223(c)-1(b). If the partner does not take steps to become a notice partner, the indirect partner's right to contest the audit's findings will depend on its ability to convince the passthrough partner (assuming the passthrough partner is a notice partner)
1 Section 6231(a).

2 Section 6231(a)(9). A disregarded entity is a passthrough partner. Primco Mgmt. Co., TCM 1997332; Rev. Rul. 2004-88, 2004-2 CB 165. A TEFRA proceeding of a pass-through partner cannot affect the treatment of items originating with lower-tier partnerships. Instead, lower-tier items must be determined in separate proceedings involving those partnerships. Sente Inv. Club Partnership of Utah, 95TC 243 (1990).

3 Section 6231 (a)(10).

4 One of the IRS's 2012 goals was to increase the tax compliance of high-income or high-wealth taxpayers. The Service is testing a new audit approach that focuses on those taxpayers who control multiple or tiered entities or have more than one flow-through business. Internal Revenue Service, Budget-in-Brief FY 2012, available at http://www.irs.gov/pub/newsroom/budget-in-brief2012.pdf; "Global High-Wealth Audits Growing, Subject to LB\&l Procedures," 2012 TNT 34-14.

5 Section 6223(a).

6 Section 6223(c)(1); Reg. 301.6223(c)-1.

7 Rigas, 110 AFTR2d 2012-5220 (CA-5, 2012).
8911 F. Supp. 1275, 77 AFTR2d 96-541 (DC Alaska, 1995), aff'd 131 F.3d 1289, 80 AFTR2d 97-7959 (CA-9, 1997).

910

10 Section 6223(c)(3).

11 Section 6223(h). If the pass-thru partner is a partnership, the tax matters partner (TMP) of the pass-thru partnership is responsible for complying with this forwarding requirement. Reg. 301.6223(h)-1(a)

12 Section 6230(f); Vander Heide, TCM 1996-74.

13 Harvey, TCM 1992-67; Fein, TCM 1994-370.

14 CCA 200951035.

15 TCM 1994-412, rev'd 88 F.3d 821, 78 AFTR2d 965257 (CA-9 1996).

$16 / d$.

17 Section 6223(b)

18 See generally Prescott, "Jumping the Shark: The Case for Repealing the TEFRA Partnership Audit Rules," 11 Fl. Tax Rev. 503 (2011) (evaluating the costs and benefits of TEFRA).

19 Elliott, "Audit Proof? How Hedge Funds, PE Funds, and PTPs Escape the IRS," 2012 TNT 1411 (noting estimates suggesting that, had the IRS generated assessments for all of the direct and indirect partners of the two largest publicly traded partnerships last year, the Service's annual limit would have maxed out, leaving it unable to send notices to partners of any other TEFRA partnerships).

20 General Explanations of the Administration's Fiscal Year 2013 Revenue Proposals, 2012 TNT 30-32. Under President Obama's proposal, adjustments would be made at the partnership level and would flow through to the partners for the year in which the adjustment takes effect; only the partnership could request a refund; and the partners would not have the right to participate in partnership-level administrative proceedings. These provisions currently apply only to electing large partnerships. President Obama's proposal would require them to apply to any partnership with 1,000 or more partners. Section 6240-55. Alternatively, the authors suggest another reform idea, which would alleviate the burden on the IRS. An adjustment could result only in a partnership-level tax or refund except to the extent that the partnership or its partners provide the partner-level information to allow the IRS to make the assessment or abatement at the partner level. 
to file a protest or a petition for readjustment.

When the pass-through partner files a petition for readjustment in a U.S. district court or the U.S. Court of Federal Claims, another issue arises that is unique to multi-tiered entities. For these courts to have jurisdiction over a partner's petition for readjustment, the partner is required to deposit with the IRS the amount by which the partner's tax liability would increase, if the partner's return were made consistent with the partnership return as adjusted by the FPAA. ${ }^{28}$ The deposit only covers the potential increased tax liability for the filing partner, rather than all partners. ${ }^{29}$

A pass-through partner, however, is required to deposit an amount based on the potential tax liability of "each indirect partner holding an interest through the pass-through partner." 30 The IRS has interpreted Reg. 301.6226(e)-1(a)(1) as requiring the deposit amount to include the total impact on tax liability of indirect partners, even if some of the changes to the indirect partner's tax liability stem from an interest in a separate passthrough intermediary and not the passthrough partner filing the petition. ${ }^{31}$ In Russian Recovery Fund, Ltd., the court of federal claims agreed with this interpretation. ${ }^{32}$

This calculation method can require a dramatically higher deposit than might be expected. For example, in
Russian Recovery Fund, Ltd., the passthrough partner deposited $\$ 50,000$, which represented the amount that the indirect partners' tax liability would be increased as a result of the indirect partners' interest in the pass-through partner. ${ }^{33}$ The amount of the deposit including the impact to the indirect partners' total tax liability (including the indirect partners' interest in the source partnership held through other pass-through intermediaries) was over $\$ 8$ million. Fortunately, incorrectly calculated deposits will not deprive a court of jurisdiction so long as the partner made a good faith attempt to satisfy the deposit requirement and any shortfall in the amount required to be deposited is timely corrected. ${ }^{34}$ Courts have liberally interpreted the good faith requirement. ${ }^{35}$

One open issue is whether a partner with a direct interest as well as an indirect interest in the source partnership may be required to deposit the total impact on his or her tax liability by redetermination of the partnership items. The regulations appear to require the partner to deposit the total impact on his or her tax liability, including through any indirect interest. This interpretation is the most consistent with the IRS's approach above.

The deposit requirement also presents a planning opportunity and another reason for an indirect partner to become a notice partner. If the partners anticipate litigation and want to file the petition for readjustment in a U.S. district court or the U.S. Court of Federal Claims, then the indirect partner with the smallest potential tax liability could file the petition and make the deposit, yet all other partners could still participate in the proceeding without filing a deposit. 36

Right to Strike Own Settlement. An indirect partner's right to strike his or her own administrative settlement with the IRS hinges on whether the indirect partner is a notice partner or whether the indirect partner has filed a statement with the IRS providing that the TMP does not have the authority to bind the indirect partner. ${ }^{37}$ The definition of notice partner is not clear if the partnership is subject to the large partnership rule and the IRS has the indirect partner's name, address, and indirect profits interest in the partnership. In these situations, an indirect partner who wants to preserve his or her right to resolve the tax liability should either form a $5 \%$ notice group or file a statement with the IRS denying the TMP the authority to enter into a settlement on the partner's behalf. If an indirect partner is not a notice partner, the indirect partner can be bound to a settlement by either the TMP or the pass-through partner through which the indirect partner holds its interest in the source partnership. ${ }^{38}$

While pass-through partners have the authority to bind indirect partners
21 Joint Report by the White House and the Department of the Treasury, The President's Framework for Business Tax Reform, Washington D.C., (February 2012), available at http://www.treasury.gov/ resource-center/tax-policy/Documents/ The-Presidents-Framework-for-Business-TaxReform-02-22-2012.pdf.

22 Elliott, "Audit Proof? How Hedge Funds, PE Funds, and PTPs Escape the IRS," 2012 TNT 141-1.

23 Id.; see Section 6224(c)(3).

24 Section 6224(a); Reg. 301.6224-1(a).

25 Section 6627(a). Given the many rights that hinge on whether a partner is a notice partner, there was some question as to whether an indirect partner could file an AAR. Recently, the Chief Counse issued guidance clarifying that an indirect partner in a TEFRA partnership is a "partner" for purposes of filing an AAR. According to the CCA, "[t]he indirect partner must show how the source partnership items flow through the tier pass-thru partner before getting to its Form 1040 in order for us to process the request-the burden is on him to show how he is entitled to a refund. The claim can be denied if he does not do so." CCA 201125039.

26 Reg. 301.6224(a)-1. The TEFRA rules require the TMP to notify partners of only the following events: closing conferences with the auditor; proposed adjustments, rights of appeal, and requirements for filing a protest; the time and place of the Appeals conference; the acceptance by the IRS of any settlement offer; the extension of the statute of limitations; the filing of an AAR; the filing of a petition for judicial review, the appeal of a judicial determination; and any final judicial determination. Reg. 301.6223(g)-1(b). If a partner wants to participate in the audit proceedings, the partner should arrange with the TMP to be informed more completely.

27 Section 6226(b)(1).

28 Section 6226(e). This requirement is similar to the "full payment" rule of Flora, 362 U.S. 145, 5 AFTR2d 1046 (1960). The deposit is based only on the potential increased tax liability and not interest and penalties. Reg. 301.6226(e)-1(a)(1).

29 Reg. 301.6226(e)-1(a)(1).

30 Reg. 301.6226(e)-1(a)(1). Section 6226(a)(2), (3).

31 Russian Recovery Fund, Ltd., 105 AFTR2d 2009310 (Fed. Cl. Ct., 2009).

32 Id. In Russian Recovery, the Court of Federal Claims also addressed whether Section 6226(e) requires the partner to deposit either (1) the partner's potential tax liability for the specific year the
FPAA was issued; or (2) the partner's total tax liability stemming from all years affected by the FPAA. The court concluded that the partner was required to deposit the partner's total tax liability stemming from all years affected by the FPAA. A later decision of the Court of Federal Claims reached a contrary result. In Prestop Holdings, LLC,106 AFTR2d 2010-7246 (Fed. Cl. Ct., 2010) the court interpreted Section 6226(e) as requiring the partner to deposit only the amount of the partner's tax liability for the specific year the FPAA was issued because the statute refers to a singular "return" and not "returns."

33 See Note 31, supra.

34 Section 6226(e)(1).

35 See Gail Vento LLC, 108 AFTR2d 2011-7113 (DC V.I., 2011), for a survey of relevant cases.

36 Section 6226(c).

37 Section 6224(c)(3). The TMP may not bind (1) notice partners, (2) members of a notice group, or (3) members who file a statement with the IRS providing that the TMP does not have the authority to enter into a settlement on behalf of such partner.

38 Section 6224(c)(1). 
to an administrative settlement, it is not clear whether they have the authority to bind indirect partners in a judicial settlement. The pass-through partner may not be considered a "party" to the judicial proceeding. Tax Court Rule 247(a) defines the parties to a TEFRA proceeding as partners who satisfy Sections 6226(c) and (d). While a pass-through partner should meet the technical definitions in Sections 6226(c) and (d), Section 6226(d) is titled "Partner Must Have Interest in Outcome." Commentators have pointed out that a pass-through partner does not have an interest in the outcome because-by definition - the partnership items flow through the pass-through partner to the indirect partners. ${ }^{39}$ This issue was raised by the taxpayer in Chomp Associates $\mathbf{4 0}^{\mathbf{0}}$ but was not resolved by the Tax Court. Therefore, it remains an open issue and one that indirect partners should address by becoming notice partners.

\section{Extended Statute of Limitations for Unidentified Partners}

Indirect partners have the unique disadvantage of being subject to an extended statute of limitations. Generally, the statute of limitations for the assessment of partnership items is three years after the later of either the date the partnership return was filed or the last day for filing the return.41 However, Section 6229(e) extends the statute of limitations for "unidentified partners" until one year after the partner has been identified to the IRS. Specifically, the extended statute of limitations in Section 6229(e) applies if the name, address, and taxpayer identification number of a partner are not furnished on the partnership return and either:

1. The IRS mailed a FPAA before the expiration of the partnership statute of limitations.

2. The partner failed to notify the Service of his or her inconsistent treatment of partnership items pursuant to Section 6222.

Because indirect partners are likely not identified on the partnership return, indirect partners are highly likely to be subject to this extended statute of limitations unless they provide an identifying statement to the IRS. 42

A partner who is not identified on the partnership return will remain "unidentified" until it files a statement with the IRS that includes its name, address, and taxpayer identification number in accordance with Reg. 301.6223(c)-1.43 Identifying information that does not satisfy the regulatory requirements will not trigger the oneyear statute of limitations. For example, in Costello, $\mathbf{4 4}$ the district court found that the listing of the indirect partner on the pass-through partnership's return did not satisfy the regulatory identification requirement for the source partnership. Therefore, the statute of limitations for the assessment of partnership items from the source partnership was not tolled for the unidentified indirect partner.

Similarly, in Gaughf Properties, L.P., 45 the Tax Court held that information obtained about indirect partners from an IRS summons issued to KPMG did not satisfy the technical requirements of Reg. 301.6223(c)-1(b). Specifically, the information:

- Was not filed with the service center where the partnership return was filed.

41 Section 6229(a).

42 Once the indirect partner notifies the IRS of his or her interest in the source partnership, the statute of limitations is extended for one year after such notification. Section 6229(e). However, filing the notice after the FPAA is issued likely will trigger a partner-level assessment. Therefore, the benefit of closing the statute of limitations likely would come at a cost.

43 Reg. 301.6229(e)-1(a); Reg. 301.6223(c)-1(b). This is the same statement that an indirect partner can provide to become a notice partner.

44765 F. Supp. 1003, 68 AFTR2d 91-5307 (DC Calif., 1991).

45 139TC No. 7 (2012)

46 FSA 1998-272 (4/13/1992).
- Did not explain that the statement was furnished to correct or supplement earlier information with respect to the partners in the partnership.

An indirect partner that does not file an identifying statement is subject to the extended limitations period if the partner takes an inconsistent position on its return and fails to notify the IRS. An inconsistent position can be taken both intentionally and unintentionally. For example, an individual or entity may not be aware that it has an interest in a source partnership and, therefore, may fail to include partnership items on its return. Field Service Advice 1998-272 provided guidance about a trust that owned an interest in a partnership subject to a TEFRA audit.46 The IRS entered into a settlement agreement with the trustee. The IRS later determined that the trust was a grantor trust. The IRS took the position that the extended statute of limitations under Section 6229(e) applied to the grantor because: 1. The grantor was not listed on the partnership's tax return.

2. The grantor (likely believing the trust was the partner in the partnership) had not included any partnership income in his return.

The grantor could have protected itself either by furnishing its identifying information to the IRS or by filing a notice of inconsistent treatment.

\section{Conclusion}

In many ways, TEFRA reduced the procedural burden on partners by streamlining the process and reducing overall audit costs. In exchange for this benefit, TEFRA's procedures in many cases shift the notice burden to passthrough partners and limit an indirect partner's right to control the resolution of his tax liability. Pass-through partners and indirect partners should approach a TEFRA audit with caution. A pass-through partner should take care to comply with TEFRA's notice requirements to avoid potential liability to its partners. Likewise, indirect partners should protect their rights to participate in partnership-level proceedings and to control the resolution of their own tax liability. 